\title{
ОСОБЕННОСТИ ПЕРЕВОДА КОНСТРУКЦИЙ С ПРЕДИКАТАМИ СОСТОЯНИЯ С РУССКОГО ЯЗЫКА НА АНГЛИЙСКИЙ
}

\author{
И. Н. Яковлева, О. В. Спиридовский \\ Воронежский государственный университет
}

\section{TRANSLATION OF STATIVE PREDICATES FROM RUSSIAN INTO ENGLISH}

\author{
I. N. Yakovleva, O. V. Spiridovsky \\ Voronezh State University
}

\begin{abstract}
Аннотация: актуальность данного исследования заключается в том, что оно углубляет и систематизирует познания о конструкииях с предикатами состояния, их семантико-функциональных и формально-грамматических особенностях, а также особенностях их перевода с русского на английский язык. В статье дается краткая характеристика категории состояния в русском языке, раскрывается ее содержание и способы языковой репрезентации. Также в работе описываются различные синтаксические модели с предикатами состояния в русском и английском языках и их особенности. В статье исследуются различные переводческих решения и трансформации, применяемые при переводе предикатов состояния в повести В. Войновича «Шапка» с русского на английский язык, а также дается оценка их эффективности с точки зрения сохранения функционально-стилистических особенностей текста оригинала. Результаты данного исследования могут быть использованы в теоретических работах, посвященных анализу переводческих стратегий, применяемых для перевода языковых единии, передающих значение состояния в художественном тексте. Выводы, сделанные в результате анализа перевода конструкиий с предикатами состояния с русского на английский язык, могут помочь практикуюшим переводчикам избежать случаев перевода, нарушающих норму и узус переводящего языка и выбрать наиболее удачные переводческие решения.
\end{abstract}

Ключевые слова: состояние, категория, предикат, перевод, трансформация.

\begin{abstract}
: the article specifies and systematize the knowledge of stative predicates: their function, semantics, grammar and translation from Russian into English. The paper also deals with the problem of the category of state, its meaning and linguistic representation. All the above determines the topicality of this research. The research focuses on possible translator choices and translation techniques used for translation of stative predicates from Russian into English in "The Fur Hat" novel by Vladimir Voinovich, which are assessed in the context of maintaining of function and style of the source text. The results of this research can be used for the analyses of constructions with stative predicates and their translations in a literary text. The arguments and findings can help translators choose the best translation technique.
\end{abstract}

Key words: state, category, predicate, translation, translation technique.

\section{Введение}

Состояние относится к универсальным языковым категориям, которые составляют основу языковой картины мира и берут начало еще в античной языковедческой традиции. Аристотель дал определение состоянию в своем трактате «Категории»: «Преходящими свойствами или состояниями называются та- кие качества, которые легко поддаются колебаниям и быстро изменяются, каковы, например, тепло и холод, болезнь и здоровье и все тому подобные [состояния]» [1, с. 74]. Всего он выделял 10 категорий: сущность, количество, качество, отношение, место, время, положение, состояние, действие, претерпевание, которые считал одновременно и категориями

(С Яковлева И. Н., Спиридовский О. В., 2021

Контент доступен под лицензией Creative Commons Attribution 4.0 License. The content is available under Creative Commons Attribution 4.0 License. 
языка, и категориями мышления, присущими любому языку.

В советском языкознании первой половины ХХ в. появляется термин «категория состояния», предложенный Л. В. Щербой. Щерба относил к категории состояния особый лексико-грамматический разряд слов, обладающих такими признаками, как «неизменяемость, с одной стороны, и употребление со связкой - с другой», например: «печален, жаль, в сознании, в сюртуке, пора, надо, должен, намерен, светло, холодно, сапоги маль мне» [2, с. 89]. В. В. Виноградов относил к категории состояния «несклоняемо-именные и наречные слова, которые имеют формы времени (для прошедшего и будущего времени аналитические, образованные посредством присоединения соответствующих форм связки быть) и употребляются только в функции сказуемого, например: не в духе, вне себя, в памяти, в сознании, рад, должен, намерен, горазд, солон, неймется, неможется, нездоровится, не терпится, пора, жаль» [3, с. 332]. Категория состояния выделялась также такими выдающимися советскими лингвистами того времени, как А. М. Пешковский и А. А. Шахматов. В дальнейшем состояние изучалось в отечественном языкознании в качестве типа предиката [4; 5], языкового концепта [6], синтаксического концепта [7], семантической универсалии [8].

\section{Постановка проблемы}

В нашей работе мы рассматриваем категорию состояния как универсальную языковую категорию, реализующуюся на предикативном уровне. Под термином «предикат» вслед за Н. Д. Арутюновой мы понимаем «указание на признак предмета, его состояние и отношение к другим предметам».

В отечественном языкознании для обозначения предиката в составе предложения используется термин-калька «сказуемое», который скорее относится к способу выражения предиката. В связи с этим мы в ходе исследования семантики предикатов состояния обращаемся к изучению различных, с формальной точки зрения, синтаксических образований, представляющих разные типы сказуемого: простое глагольное, составное глагольное, составное именное, второе и второстепенное сказуемые.

Термины «второе» и «второстепенное сказуемое» были впервые предложены А. А. Шахматовым [9], а затем подробно описаны А. М. Ломовым в работе «Типология русского предложения» [10]. Согласно А. М. Ломову в предложениях типа: Они вернулись домой усталье предикатив усталье - это второе сказуемое, а в предложении Их нашли цуельли и невредимыми член предложения цельлми и невредимыми является второстепенным сказуемым.
При выполнении сопоставительного анализа мы в нашей работе рассматриваем в качестве второго сказуемого выделяемый авторами некоторых английских грамматик Subject Complement - член предложения, который употребляется с некоторыми полнозначными глаголами, выполняющими роль связки, например: I lay wide-awake listening to the rain banging at the window pane. В качестве второстепенного сказуемого мы рассматриваем Object Complement - член предложения, распространяющий дополнение: His jokes made me ill at ease.

С точки зрения семантики исследователи делят предикаты, обозначающие состояние одушевленного субъекта, на предикаты физического (физиологического) (Мне жарко, Ее знобит, Она голодная, Ему не спится и т. д.); эмоционального (Мне скучно, Она волнуется, Я в недоумении, Он в ярости, Они веселятся и т. д.) и ментального (Студенты были внимательны, Он был совершенно невменяем, Я до сих пор в раздумьях и т. д.) состояния.

Предикаты состояния образуют целый ряд синтаксических моделей. Под синтаксической моделью мы понимаем «минимально достаточное сочетание взаимообусловленных синтаксических форм, образующее коммуникативную единицу с определенным типовым значением» [11, с. 25].

В повести В. Войновича «Шапка» нам удалось обнаружить следующие синтаксические модели, образуемые предикатами состояния:

- глагольная. К ней относятся: простое глагольное сказуемое (предикат выражен полнозначным глаголом: Он в таких случаях пугался, смущался $и$ пытался меня уверить, что ни на какую печатную критику и не надеется); составное глагольное сказуемое (связка + инфинитив: Я начал волноваться); связка в виде полнозначного глагола + второе сказуемое, выраженное деепричастием: Ефим осторожно вытаскивал папку и вручал мне, одновременно как бы и смущаясь, и оказывая честь; связка в виде полнозначного глагола + второе сказуемое, выраженное причастием: Униженный, оскорбленный, оплеванный Ефим вышел из кабинета;

- адъективная. Предикат выражен составным именным сказуемым (глагол-связка (часто нулевая) + прилагательное: Bbl, nanama, извиняюсь, пьяный или больной?);

- предложно-именная. Предикат выражен глаголом-связкой + существительное с предлогом (Eфuм с удовольствием смотрит на сына);

- номинативная (субстантивная). К данной модели относятся односоставные номинативные предложения, такие как: У него депрессия; На улице жара. В предложениях данного типа «существительное в именительном падеже совмещает два значения - 
назывное и бытийное» [12, с. 101]. По мнению Н. Д. Арутюновой, такие предложения «представляют собой случай субстантивного представления предикатных значений и характеризуют синтаксическую специфику русского языка» [13, с. 791];

- безлично-предикативная. Предикат выражен безлично-предикативным наречием в безличном предложении (Отказывать старику было неудобно) либо безличным глаголом с субъектом в форме дательного или винительного падежа (Савелию не спалось; Меня тошнило).

Рассмотрим отдельно каждую из указанных выше моделей и основания для ее выбора.

Глагольная модель. «Как известно, прототипическое значение глагола как части речи - это значение “действия” (в узком смысле слова). По-видимому, это может объяснить появление очевидного оттенка в значении глагольных предикатов состояния по сравнению, скажем, с безлично-предикативной моделью. Глагольные предложения, передавая состояние, обычно указывают на его внешнее проявление» [14, с. 72], например: Лукин весь побледнел, задрожал, трясущчимися руками полез в боковой карман, вынул бумажник, достал из него маленькую пожелтевшую фотографию. Как отмечал А. М. Пешковский: «Мы скорее скажем “он радуется как ребенок”, чем “он рад как ребенок”, потому что “радуется” указывает на какието жесты, выражение лица, словом на какое-то проявление радости, чем и больше подходит к ребенку нежели “рад”» [15, с. 97]. «В отличие от безлично-предикативных предложений, в которых, как уже говорилось, подчеркивается пассивность субъекта, испытывающего состояние, глагольная модель, напротив, акцентирует внимание на том, что субъект “активно”, переживает состояние. Состояние не представляется здесь как что-то абсолютно безотчетное, навязанное какой-то внешней по отношению к субъекту силой, поэтому вполне можно сказать: Мне как-то грустно сегодня; Не пойму, почему мне так неловко (Н. Баранская), но предложения: Я как-то грущу сегодня или Не пойму, почему я грущу сегодня - кажутся неестественными. Глагольная модель с предикатом состояния бывает наиболее предпочтительна в тех случаях, когда необходимо описать состояние субъекта, выражающееся в его поведении: Галя волновалась, просила, чтобы непременно спеть “Друзья”, прижимала руки к груди (Т. Толстая); Мать стала сердиться, дергать ее, трепать (Н. Баранская)» [14, c. 72-73].

Безлично-предикативная модель. И. П. Распопов писал, что «в абсолютном большинстве случаев безличные предложения могут трактоваться... как производные от личных (как их своеобразные трансформы)» [16, с. 471]. «Опираясь на данное заключение, можно с достаточно большой степенью уверен- ности заключить, что предложения типа $E$ мy не спится являются производными от предложений типа Он не сnит. При сохранении глагольного предиката именительный падеж субъекта заменяется дательным. Данная трансформация обеспечивает введение особого модусного смысла. Согласно теории модуса и диктума, которая связывается с именем Шарля Балли, модус отражает коррелятивную операцию, производимую мыслящим субъектом, отражает цели и условия речевого акта и противопоставляется диктуму, который отображает предметную ситуацию (событие, положение вещей). В рассматриваемых безличных предложениях модусный смысл можно определить, как существование неких условий, не зависящих от усилий и воли субъекта, способствующих или препятствующих успешному осуществлению описываемых ситуаций. Употребление подлежащего в форме дательного падежа подчеркивает дезактивацию субъекта» [14, с. 68-69]. Г. А. Волохина считает, что «можно предположить, что обозначение претерпевающего лица (пациенса) формой дательного падежа связано с формой дательного падежа адресата, в свою очередь восходящего к форме дательного падежа конечного пункта перемещения. Некое состояние адресуется лицу, которое пассивно воспринимает это состояние, будучи как бы пунктом его назначения» $[17$, с. 146]. «Расположенность или нерасположенность субъекта к тем или иным действиям воспринимается как его состояние, навязанное внешними обстоятельствами, ощущения человека изображаются как результат воздействия неких стихийных сил на его организм или сознание. Специфичность дополнительного модусного смысла, характеризующего эту модель, обусловливает ее уникальность, непереводимость ее смысла в другие модели» [14, с. 69].

Адъективная модель. В современном русском языке позицию предикатива могут занимать как полные, так и краткие формы прилагательных. Однако у полных форм прилагательных эта функция появилась лишь в конце XVIII - начале XIX в., а до этого времени синтаксические роли полного и краткого прилагательного были строго дифференцированы: полное обозначало определенный уже известный признак, а краткое - новый. Соответственно, полные прилагательные употреблялись в функции определения, а краткие выполняли функцию сказуемого. Со временем обе формы стали употребляться в составе предикатов, в частности предикатов состояния, однако при этом они демонстрируют различия в своей семантике. В. В. Виноградов пишет: «В сущности, при предикативном употреблении полных форм имен прилагательных [...] происходит превращение качества в качественное состояние, протекающее во времени и приписываемое лицу или предмету» [3, c. 263]. Так в предложении: Какой ты холодный!, 
обращенном к человеку, вошедшему с холода, полное прилагательное в составе предиката обозначает временный признак (физическое состояние) субъекта. Часто для того, чтобы акцентировать внимание на временности признака, используются временные маркеры, как правило наречия, указывающие на соотнесенность признака с определенным моментом или отрезком времени, например: сегодня, сейчас, вчера, в последнее время и т. д.: Фима, как потом говорили, в тот момент казался совершенно спокойHblM.

Основанием для выбора адъективной модели, вероятно, является необходимость сделать акцент на самом признаке, а не на характере его протекания во времени или способе существования. Согласно Е. С. Кубряковой: «Если внимание сфокусировано на признаке (части) объекта так, чтобы сам этот процесс не требовал времени и был сосредоточенным в одно мгновение, - этот признак скорее всего будет обозначен прилагательным < ..> Если же наблюдение за признаком требует времени, а внимание к объекту в стадиях его изменения как бы распределено во времени, такой признак скорее всего будет обозначен глаголом, и он представляется нашему уму как процессуальный» [17, с. 189]. Таким образом, если мы хотим сообщить о временном, не зависящем от воли или желания субъекта признаке, например негативном физиологическом состоянии, мы скорее всего скажем: Бабушка больна. А если хотим сфокусироваться на протекании признака во времени, то скажем: Бабушка болеет уже неделю. *Бабушка больна уже неделю кажется менее естественным.

Предложно-именная модель. Данная модель, которая, как правило, представлена предлогом: в/на/ nри/без/с/под + существительное, конкретизирующее то или иное физиологическое или психологическое состояние одушевленного субъекта, характерна для ситуаций, в которых субъект полностью охвачен тем или иным состоянием: От известия Кукуша пришла в ужсас; Фишкин был на взводе; Но он же при смерти!; Фима упал в кресло без сил; Тот посмотрел на Бромберга с удивлением, поморщился, отодвинул пепельницу и, обрашаясь ко всем, негромко сказал...; По-моему, Баранов был под впечатлением.

Модели с предикатами состояния при использовании в речи подвергаются различным структурно-семантическим модификациям, например, фазисным и модальным. Фазисные модификации реализуются за счет усложнения основной модели фазисными модификаторами начала (начал злиться, стал бледным, сделалось дурно, пришел в ужас, У него развилась депрессия, стало темно), конца (перестала беспокоиться, У него закончилась депрессия, перестало хотеться) и продолжения состояния (продолжает горевать, оставался спокоен, оставался в полной уверенности). К модальным модификациям относятся модификации обнаружения (оказался больным, оказался в нетрезвом состоянии) и субъективного восприятия состояния (казался спокойным).

Предикаты состояния могут быть представлены в аналитической форме при помощи таких слов, как чувство, состояние, настроение; чувствовать, исnылтывать, ощущаты, переживать в сочетании с лексемой, конкретизирующей состояние (существительным или прилагательным): Студенты все время были в напряжснном состоянии; Это было так неожиданно, что Василий Степанович даже не сразу почувствовал боль и т. д.

Исходя из вышесказанного, можно сделать вывод, что в русском языке существует целый ряд синтаксических моделей с предикатами состояния, представленных в различных формах и структурно-семантических модификациях, из которых говорящий выбирает ту, которая наиболее соответствует контексту. По словам Г. В. Колшанского, «смысл высказывания формируется и определяется коммуникативно-познавательной установкой говорящего, решающим условием формирования которой является сообщение точно-заданного смысла в пределах определенного текста» $[18$, с. 60$]$.

\section{Сопоставительный анализ русских предикатов состояния и вариантов их перевода на английский язык}

Теперь рассмотрим, как синтаксические модели с предикатами состояния, используемые В. Войновичем в его повести «Шапка», трансформировались при переводе произведения на английский язык. Повесть в переводе называется “The Fur hat", автор перевода - Сьюзан Браунсбергер (Susan Brownsberger).

Как известно, для достижения переводческой эквивалентности и семантико-стилистической адекватности переводчики используют различные переводческие трансформации. В. Н. Комиссаров пишет, что переводческие (межъязыковые) трансформации - «это преобразования, с помощью которых можно осуществить переход от единиц оригинала к единицам перевода в указанном смысле» [19, с. 172]. Л. С. Бархударов считает, что переводческие трансформации - это «различные отличающиеся по своей природе преобразования, зачастую используемые переводчиком для достижения переводческой эквивалентности и необходимые ему, поскольку формальные и семантические системы исходного языка и переводящего языка существенно разнятся» [20, c. 190].

В. Н. Комиссаров в зависимости от того, какие единицы исходного сообщения будут подвергаться трансформациям, выделяет лексические, грамматические и комплексные лексико-грамматические пе- 
реводческие трансформации, т. е. такие, «где преобразования либо затрагивают одновременно лексические и грамматические единицы оригинала, либо являются межуровневыми, т. е. осуществляют переход от лексических единиц к грамматическим и наоборот» $[19$, с. 172].

К лексическим типам трансформаций В. Н. Комиссаров относит: «переводческое транскрибирование и транслитерацию, калькирование и лексико-семантические замены (конкретизацию, генерализацию, модуляцию)» [19, с. 172].

Среди грамматических трансформаций им выделяются: «синтаксическое уподобление (дословный перевод), членение предложения, объединение предложений, грамматические замены (формы слова, части речи или члена предложения)» [19, с. 173].

Что касается комплексных лексико-грамматических трансформаций, В. Н. Комиссаров выделяет среди них следующие типы: «антонимический перевод, экспликация (описательный перевод) и компенсация» $[19$, с. 73$]$.

В исследуемых текстах нам удалось обнаружить следующие переводческие трансформации.

Лексико-семантические замены. Лексико-семантической замена по В. Н. Комиссарову - «это способ перевода лексических единиц оригинала путем использования в переводе единиц ПЯ, значение которых не совпадает со значениями исходных единиц, но может быть выведено из них с помощью определенного типа логических преобразований» [19, c. 174], например:

Виктор, ты что, с ума сошел?»-стал отталкивать Черпакова ногами. - Victor Petrovich, get hold of yourself! - he shouted and kicked at Cheprakov.

Синтаксическое уподобление (дословный перевод). Синтаксическое уподобление или дословный перевод по В. Н. Комиссарову - «это способ перевода, при котором синтаксическая структура оригинала преобразуется в аналогичную структуру ПЯ. Этот тип «нулевой» трансформации применяется в тех случаях, когда в ИЯ и ПЯ существуют параллельные синтаксические структуры. Синтаксическое уподобление может приводить к полному соответствию количества языковых единиц и порядка их расположения в оригинале и переводе» [19, с. 178]. Примеры синтаксического уподобления в исследуемых текстах:

1) глагольная модель с простым глагольным сказуемым:

Однажды, впрочем, я сильно на Ефима рассердился... - One day I blew ир.

Он просиял. - Не bеamed.

2) глагольная модель со вторым сказуемым:

Пересилив себя, Ефим сел за машинку. Regaining his composure, Yefim typed.
«Тьфу!»-сплюнул Ефим и в досадехлопнул себя по колену. - Yefim spat and hit his knee in irritation.

Чувствуя во всем теле жалкую суетливость, Ефим продвинулся к столу, на ходу нелепо ульбаясь и кланяясь. - Feeling an awful fidgetiness throughout his body, Yefim advanced towards the desk, smiling and bowing absurdly as he walked.

Он стоял потрясенный. - His visitor stood stunned.

Униженный, оскорбленный, оплеванный Ефим вышел из кабинета. - Insulted, injured, spurned, Yefim left the office.

Грамматические замены (формы слова, части речи или члена предложения). Грамматические замены по В. Н. Комиссарову - «это способ перевода, при котором грамматическая единица в оригинале преобразуется в единицу ПЯ с иным грамматическим значением. Замене может подвергаться грамматическая единица ИЯ любого уровня: словоформа, часть речи, член предложения, предложение определенного типа» [19, с. 180-181]. Рассмотрим некоторые примеры.

Грамматическая замена, при которой глагольная модель предиката заменяется адъективной:

Будучи скептиком, я в этом глубоко сомневался. - I was sceptical.

Подожди, не горячись, - попыталась меня утихомирить жена. - Now don't get excited, my wife said soothingly.

Впрочем, Ефим злился не только на Баранова, но и на себя самого. - Yefim was as angry with himself as he was with Kostya.

На этом месте он сам себя остановил, перечитал написанное и удивился. - Rereading what he had written, he was amazed.

Ефим просто опешил и не знал, что сказать. Yefim was flabbergasted.

Савелию жарко. Он изнывает. - He is hot, exhausted.

Глагольная модель заменяется предложно-именной:

Он засуетился, немедленно извлек из портфеля средних размеров блокнот с Юрием Долгоруким на обложке. - With anxious haste he drew from his attache case a medium-sized notepad.

Ефим сжсался, сконфузился и улыбнулся поэту. - He retreated in confusion, smiling foolishly at the poet.

Загородив собою дверь, он смотрел на меня, не выражсая ни радости, ни огорчения. - He looked at me with an expression of neither pleasure nor displeasure.

Безлично-предикативная модель заменяется глагольной:

Отказывать старику было неудобно. - Не couldn't very well say no to an old man. 
А мне все равно, - дерзко сказал Ефим. - I don't care, - Yefim snapped.

Да ничего, ничего, даже рассказывать неохота. Everything's just fine I don't feel like talking about it.

Ему было жсаль меня, чуждого высоких порывов, но спорить, он понимал, бесполезно. - Hе pitied me, a stranger to noble impulses.

Настроение испортилось. Писать уже не хотелось. - His mood was spoiled. He didn't feel like writing any more.

Безлично-предикативная модель заменяется адъективной:

Савелию жсарко. Он изнывает. - He is hot, exhausted.

Предложно-именная модель заменяется адъективной:

От известия Кукуша пришла в ужас. - Kukusha was horrified at the news.

Антонимический перевод - «это лексико-грамматическая трансформация, при которой замена утвердительной формы в оригинале на отрицательную форму в переводе или, наоборот, отрицательной на утвердительную сопровождается заменой лексической единицы ИЯ на единицу ПЯ с противоположным значением» [19, с. 183]:

С ним и раньше бывало, что он писал, находясь как бы не в себе. - This had happened before to him - writing in a frenzy.

Ну, Кукушенька, ты чего? - залебезил Ефим. Now, Kukusha, sweetie, don't be mad.

- Ваш друг, - сказал я, - по-моему, совсем с пантальку сбился. - Yои friend - I said, is out of his mind, in my opinion.

Что касается модификаций конструкций с предикатами состояния в исследуемых текстах, в основном они сохраняются при переводе на английский язык.

1. Он решил это совершенно твердо (так же твердо, как решал это тысячу раз) и почувствовал (в тыссячу первый раз) облегчение и успокоенность. He had made up his mind and immediately felt relieved. В данном примере предикат почувствовал облегчение u успокоенность представляет собой одновременно фазисную модификацию начала состояния и модификацию расщепления. В переводе с использованием грамматической замены сохраняется только фазисная модификация. В английском языке употребление связочного глагола в составе предиката состояния в форме Past Simple felt relieved в сочетании с наречием immediately передает значение начала состояния, как, например, в предложении Suddenly, there was silence.

2. Вернулся кмашинке и, впав в некий ражк, стал быстро-быстро стучать по клавишам, не соображая, что пuшеm. - But when he returned to his typewriter, a fit of rage overcame him and he began banging away at the keys without stopping to think. При перево- де данного предиката, наоборот, фазисная модификация начала состояния заменяется комбинацией фазисная + модификация расщепления путем добавления классификатора a fit of (rage). Конструкция a fit of rage overcame him представляет собой случай субстантивного представления предикатного значения. Таким образом, мы видим, что предложно-именная модель в русском языке была заменена номинативной в английском с помощью грамматической замены.

3. Фима, как потом говорили, казался совершенно спокоен. - Fima, they said later, seemed perfectly calm. В этом примере при дословном переводе предиката сохраняется модификация обнаружения состояния.

4. Яушел, радуясь, что Ефим так быстро вышел из своего состояния. - I left, rejoicing to see Yefim so quickly recovered. Здесь фазисная модификация окончания состояния в переводе не сохранилась. Предложно-именная модель предиката была заменена на глагольную в результате грамматической замены.

5. Выкривив обе губы в выражсении, означающем крайнюю озадаченность, Ефим покачал головой $u$ сунул лист под кипу лежавиих справа от машинки cmapых черновиков. - Pursing his lips in perplexity, Yefim shook his head. В данном примере модификация расщепления не сохранилась при переводе.

Поскольку речь героев в художественном тексте часто богата фразеологическими и метафорическими выражениями, рассмотрим возможные переводческие стратегии при переводе предикатов состояния, представляющих собой такого рода явления.

Т. А. Казакова выделяет следующие способы перевода фразеологизмов и метафор:

1) поиск идентичной фразеологической/метафорической единицы (такой способ возможен, если в языке перевода существует непосредственный эквивалент оригинальному фразеологизму);

2) поиск аналогичной фразеологической/метафорической единицы (словесно-образная основа фразеологизма на переводящем языке будет отличаться от такой основы фразеологизма на исходном языке, однако такой аналог будет иметь общее с исходным выражением значение);

3) дословный перевод фразеологизма/метафоры;

4) перевод-объяснение переносного значения фразеологизма/метафоры (при таком способе перевода происходит нейтрализация образа) [21, с. 127].

Перевод с помощью эквивалента фразеологизма/ метафоры:

Я же сльишу по твоему голосу, что ты не в себе. Что случилось? - I can tell by your voice you aren't yourself.

Перевод с помощью аналога фразеологизма/метафоры: 
Сам себе он казался мерзким рвачом и сутягой. - Yefim was filled with shame. He felt like a loathsome scheming insect.

Льсик, - встревожилась Кукуша. - Тыл, часом, не трекнулся? - Baldy, - Kukusha said, nervous. You haven't gone and lost your marbles, have you?

Люди совсем посходили с ума. - People have completely taken leave of their senses.

Виктор, ты что, с ума сошел? - стал отталкивать Черпакова ногами. - Victor Petrovich, get hold of yourself! - he shouted and kicked at Cheprakov.

Дословный перевод фразеологизма:

Он совсем на этой шапке заклинился. - He is completely fixated on this hat.

Перевод-объяснение переносного значения фразеологизма/метафоры:

Зла не хватает, честное слово! - I was never so furious in my life.

Что случилось? - вбежсала перепуганная насмерть Кукуша. - What happened? - cried Kukusha as she ran in, alarmed.

Ничего вокруг себя не видел Василий Трешкин. - Vaska Tyoshkin was transfixed.

Классификация Т. А. Казаковой, однако, не включает те случаи, когда неметафорическая единица в языке оригинала переводится с помощью метафоры или фразеологизма. Нам удалось выявить ряд таких случаев:

Каретникова Лариса Евгеньевна начала было говорить, что Василий Степанович нездоров и никого не принимает. - Karetnikov's wife, Larisa Yevgenyevna, said that Vasily Stepanovich was under the weather.

A ты что такая смурная? - But why are you so down in the mouth?

В глазах его я увидел немой укор и смутился. - I became ill at ease, feeling what he was asking with that look.

Ефим сперва растерялся. - For a moment, Yefim was thunderstuck.

Лукин весь побледнел, задрожал, трясущуимися руками полез в боковой карман, вынул бумажник, достал из него маленькую пожелтевиую фотографию. - Lukin had turned white as a sheet and started to tremble.

Кукуша опомнилась разжала пальцыы и, обозвав Лукина сволочью, в слезах выскочила из кабинета. Kukusha came to her senses.

\section{Выводы}

Таким образом, сопоставительный анализ текстов оригинала и перевода повести В. Войновича позволяет сделать следующие выводы.

Значение состояния как универсальной семантической категории при переводе на английский язык сохраняется. Случаев замены значения состояния на действие или качество нами не выявлено, что еще раз подтверждает универсальность данной категории для обоих языков. Более того, в английском переводе встречается большинство синтаксических моделей, используемых для выражения состояния в русском оригинале. Таких как глагольная (с предикатом, выраженным полнозначным глаголом и глаголом со вторым сказуемым), адъективная, предложно-именная и номинативная. Исключение составляет безлично-предикативная модель, которая является одним из самых распространенных способов выражения состояния в русском языке. Данное несоответствие абсолютно объяснимо, поскольку в английском языке такой категории, как безличное предложение, не существует в принципе.

Также при переводе на английский язык сохраняется большинство модификаций с предикатами состояния, таких как фазисные, модальные и модификации расщепления.

Различия наблюдаются на формально-грамматическом уровне в использовании разных синтаксических моделей для реализации значения того или иного состояния в оригинале и переводе исследуемого текста. Так, наиболее частотной трансформацией, наблюдаемой в английском переводе, является грамматическая замена, при которой глагольная, предложно-именная и безлично-предикативная модели заменяются на адъективную. Адъективная модель в целом используется в английском языке для выражения состояния гораздо чаще, чем другие. Это объясняется прежде всего особенностями английского языка как языка аналитического строя, для которого характерно употребление связочного глагола в предикате. Что касается русского языка, А. Вежбицкая пишет, что «если некие концепты получают именное (или глагольное) обозначение вместо адъективного, для этого должны быть достаточные семантические основания» [8, с. 119]. Как уже говорилось выше, адъективный предикат в отличие от глагольного лишь констатирует наличие состояния и не представляет его в виде процесса. В английском же языке в предложении He has been ill for a week как раз сообщается о протяженности состояния, а значение процесса достигается с помощью временной формы глагольной связки.

Интересно отметить, что прием синтаксического уподобления (дословный перевод) используется в исследуемом тексте в основном для перевода глагольной модели с предикатами состояния. Напрашивается вывод о том, что переводчик в этих случаях стремится сохранить не только функционально-стилистическое соответствие оригиналу, но и исчерпывающе передать авторский замысел и художественные особенности текста, в частности его динамику, которая, как известно, связана именно с глагольным способом выражения. 
Использование переводчиком данного произведения грамматических трансформаций не обходится без потерь. Это касается прежде всего случаев замены безлично-предикативных конструкций на адъективную модель. Как мы уже говорили выше, безличные предложения с возвратными безличными глаголами типа Мне не верится широко используются в русском языке для обозначения состояния чувствующего субъекта. Многие исследователи усматривают в этом особенность русского менталитета, отличающую его от, скажем, европейского [22; 23]. По мнению А. Вежбицкой, «именно таким способом русские очень часто рассказывают о событиях своей ментальной жизни, подразумевая при этом, что эти события просто «случаются» в их умах и что они не несут за них ответственности» [23, с. 69]. Естественно, что при замене русской безлично-предикативной модели английской адъективной моделью при переводе данный смысл будет утрачен.

Помимо грамматических замен и синтаксического уподобления в исследуемом переводе используются также лексико-семантические замены и антонимический перевод, но в гораздо меньшем числе случаев.

Что касается перевода случаев метафорического способа выражения состояния, переводчик чаще всего прибегает к переводу с помощью аналога фразеологизма/метафоры или переводу-объяснению. Первое объясняется достаточным арсеналом метафорических средств для описания того или иного состояния в обоих языках, а также распространенностью такого способа описания состояния. Перевод-объяснение (нейтрализация) используется, по нашим наблюдениям, в тех случаях, когда переводчик выбирает вариант снижения экспрессивности исходного текста при переводе в пользу либо более точной передачи смысла, либо в пользу нормы или узуса переводящего языка.

Интересны довольно многочисленные случаи повышения экспрессивности текста перевода, когда нейтральное обозначение состояния в русском языке переводится с помощью метафоры или фразеологизма на английский. Вероятно, переводчик руководствовался стремлением исчерпывающе передать смысл и ритмический рисунок оригинала, а также сохранить авторский замысел, в связи с чем заменял неметафорические выражения метафорическими, вызывающим особые лингво-культурные ассоциации у получателя текста перевода.

\section{ЛИТЕРАТУРА}

1. Аристотель. Метафизика // Аристотель. Соч. T. 1. М. : Мысль, 1976. 382 с.

2. Щерба Л. В. Языковая система и речевая деятельность. Ленинград : Наука, 1974. 428 с.

3. Русский язык (Грамматическое учение о слове) / под ред. Г. А. Золотовой. 4-е изд. М. : Рус. яз., 2001. 720 с.
4. Степанов Ю. С. Имена. Предикаты. Предложения (Семиологическая грамматика). М., 1981. 360 с.

5. Семантические типы предикатов / отв. ред. О. Н. Селиверстова. М., 1982. 365 с.

6. Бульгина Т. В., Шмелев А. Д. Языковая концептуализация мира (на материале русской грамматики). М., 1997. $576 \mathrm{c}$.

7. Волохина Г. А., Попова 3. Д. Синтаксические концепты русского простого предложения. Воронеж, 1999. $131 \mathrm{c}$.

8. Вежбицุка А. Семантические универсалии и описание языков. М. : Языки русской культуры, 1999. 740 с.

9. Шахматов А. А. Синтаксис русского языка. М. : Флинта, 2014. 720 c.

10. Ломов А. М. Типология русского предложения. Воронеж, 1994. $280 \mathrm{c}$.

11. Золотова Г. А. Очерк функционального синтаксиса русского языка. М. : Наука, 1973. 352 с.

12. Лекант П. А. Синтаксис простого предложения в современном русском языке. 2-е изд., испр. М. : Высшая школа, $1986.176 \mathrm{c}$.

13. Арутюнова Н. Д. Язык и мир человека. М. : Языки русской культуры, 1999. 896 с.

14. Яковлева И. Н. Семантическая категория состояния и средства ее реализации : дис. ... канд. филол. наук. Воронеж, 2003. $170 \mathrm{c}$.

15. Пешковский A. М. Русский синтаксис в научном освещении. М. : Языки славянской культуры, 2001. 512 с.

16. Распопов И. П. Спорные вопросы синтаксиса. Ростов-н/Д. : Изд-во Ростов. ун-та, 1981. 128 с.

17. Кубрякова E. С. Части речи с когнитивной точки зрения. М. : Языки славянской культуры, 2004. 450 с.

18. Колианский Г. В. Контекстная семантика. М. : Наука, 1980. 110 с.

19. Комиссаров В. Н. Теория перевода (лингвистические аспекты) : учебник для институтов и факультетов иностранного языка. М. : Высшая школа, 1990. 253 с.

20. Бархударов Л. С. Язык и перевод (Вопросы общей и частной теории перевода). М. : Международные отношения, 1975.258 с.

21. Казакова Т. А. Практические основы перевода. English - Russian : учеб. пособие. СПб. : Союз, 2004. $320 \mathrm{c}$.

22. Гак В. Г. Русский язык в сопоставлении с французским. М. : Русский язык, 1988. 263 с.

23. Вежбицкая А. Язык. Культура. Познание. М. : Русские словари, 1996. 411 с.

\section{REFERENCES}

1. Aristotel'. Metafizika. In: Aristotel'. Soch. Vol. 1. Moskva: Mysl', 1976. 382 p.

2. SHHerba L. V. YAzykovaya sistema i rechevaya deyatel'nost'. Leningrad: Nauka, 1974. 428 p.

3. Russkij yazyk (Grammaticheskoe uchenie o slove) / pod red. G. A. Zolotovoj. 4-e izd. M.: Rus. yaz., 2001. 720 p.

4. Stepanov Yu. S. Imena. Predikaty. Predlozheniya. (Semiologicheskaya grammatika). M., 1981. 360 p. 
5. Semanticheskie tipy predikatov / otv. red. O. N. Seliverstova. M., 1982. 365 p.

6. Bulygina T.V., Shmelev A. D. Yazykovaya kontseptualizatsiya mira (Na materiale russkoj grammatiki). M., 1997. 576 p.

7. Volokhina G. A., Popova Z. D. Sintaksicheskie kontsepty russkogo prostogo predlozheniya. Voronezh, 1999. $131 \mathrm{p}$.

8. Vezhbitska A. Semanticheskie universalii i opisanie yazykov. Moskva : Yazyki russkoj kul'tury, 1999. 740 p.

9. Shakhmatov A. A. Sintaksis russkogo yazyka. Moskva : Flinta, 2014. 720 p.

10. Lomov A. M. Tipologiya russkogo predlozheniya. Voronezh, 1994. 280 p.

11. Zolotova G. A. Ocherk funktsional'nogo sintaksisa russkogo yazyka. Moskva: Nauka, 1973. 352 p.

12. Lekant P. A. Sintaksis prostogo predlozheniya $v$ sovremennom russkom yazyke. 2-e izd., ispr. Moskva: Vysshaya shkola, 1986. 176 p.

13. Arutyunova N. D. YAzyk i mir cheloveka. Moskva: YAzyki russkoj kul'tury, 1999. 896 p.

14. YAkovleva I. N. Semanticheskaya kategoriya sostoyaniya i sredstva ee realizatsii. Dis. kandidata filol. nauk. Voronezhskij gos. un-t. Voronezh, 2003. 170 p.

Воронежский государственный университет

Яковлева И. Н., доиент кафедры перевода и профессиональной коммуникации

E-mail:yakovleva@rgph.vsu.ru

Спиридовский О. В., доиент кафедры перевода и профессиональной коммуникации

E-mail: olegspirid@mail.ru

Поступила в редакциию 9 сентября 2020 г.

Принята к публикации 29 декабря 2020 г.

\section{Для цитирования:}

Яковлева И. Н., Спиридовский О. В. Особенности перевода конструкций с предикатами состояния с русского языка на английский // Вестник Воронежского государственного университета. Серия: Лингвистика и межкультурная коммуникация. 2021. № 1. C. 65-73. DOI: https://doi.org/10.17308/lic.2021.1/3239
15. Peshkovskij A. M. Russkij sintaksis v nauchnom osveshhenii. Moskva: YAzyki slavyanskoj kul'tury, 2001. $512 \mathrm{p}$.

16. Raspopov I. P. Spornye voprosy sintaksisa. Rostov-n/D: Izd-vo Rostovskogo universiteta, 1981. 128 p.

17. Kubryakova E. S. CHasti rechi s kognitivnoj tochki zreniya. Moskva: YAzyki slavyanskoj kul'tury, 2004. $450 \mathrm{p}$.

18. Kolshanskij G. V. Kontekstnaya semantika. Moskva: Nauka, 1980. 110 p.

19. Komissarov V. N. Teoriya perevoda (lingvisticheskie aspekty): Uchebnik dlya institutov i fakul'tetov inostrannogo yazyka. Moskva: Vysshaya shkola, 1990. $253 \mathrm{p}$.

20. Barkhudarov L. S. YAzyk i perevod (Voprosy obshhej i chastnoj teorii perevoda). Moskva: Mezhdunarodnye otnosheniya, 1975. $258 \mathrm{p}$.

21. Kazakova T. A. Prakticheskie osnovy perevoda. English - Russian: uchebnoe posobie. SPb: Soyuz, 2004. $320 \mathrm{p}$.

22. Gak V. G. Russkij yazyk v sopostavlenii s frantsuzskim. M. : Russkij yazyk, 1988. 263 p.

23. Vezhbitskaya A. YAzyk. Kul'tura. Poznanie. Moskva : Russkie slovari, 1996. 411 p.

Voronezh State University

Yakovleva I. N., Associate Professor of the Translation and Professional Communication Department

E-mail:yakovleva@rgph.vsu.ru

Spiridovsky O. V., Associate Professor of the Translation and Professional Communication Department

E-mail: olegspirid@mail.ru

Received: 9 September 2020

Accepted: 29 December 2020

\section{For citation:}

Yakovleva I. N., Spiridovsky O. $V$. Translation of stative predicates from Russian into English. Proceedings of Voronezh State University. Series: Linguistics and Intercultural Communication. 2021. No. 1. Pp. 65-73. DOI: https:// doi.org/10.17308/lic.2021.1/3239 